\title{
All aboard for graduate school
}

\author{
Graduate school can be an intimidating journey to undertake. Luckily, there are plenty of sources of advice \\ to help you on the way.
}

$\mathbf{S}$ eptember is now upon us and summer is over. For some college graduates, it's back to school again as they embark on the long road to a $\mathrm{PhD}$. If you are one of this eager group of bright young things, you may be headed for the most rewarding years of your education thus far, years that will culminate in a body of work that is truly the fruit of your intellectual pursuit and drive. However, you will also face periods of hard, hard work (and times when nothing seems to work). Late one night, you may even harbor the illusion that the dodgy basement vending machine can provide a decent and (more importantly) time-saving meal, allowing you to fit in even more work. So, does the $\mathrm{PhD}$ really have to be a trial by fire or are there sources of advice available? Luckily, in this day and age, when you ask "is there anybody out there?" the internet always answers yes. So does that professor/post-doc/self-help guide/scientific society or scientific journal (including, of course, Nature).

Although advice and self-help books are not everyone's cup of tea, there are a number if tomes out there for those who prefer to read all about it. You may find Getting What You Came For: The Smart Student's Guide to Earning an MA or a PhD by Robert Peters (Farrar, Straus and Giroux) useful. The PhD Process: A Student's Guide to Graduate School in the Sciences by Bloom, Karp and Cohen (Oxford University Press) is also an excellent source, as is Graduate Research: A Guide for Students in the Sciences by Robert V. Smith (University of Washington Press). These texts cover issues from choosing a lab to feeding your thesis committee. In addition, the Science and Nature journals publish columns on topics of interest to graduate students, so it's often useful to glance over the first half of their tables of contents.

Of course, there is also e-help. Nature has a career magazine attached to its website that not only includes sections devoted to graduate students but also archives past articles (http://www. nature.com/naturejobs/magazine/graduates/index.html). Topics range as widely as personality clashes in the lab to career fairs and forums. Science and the AAAS sponsor a similarly useful resource (http://sciencecareers.org), and http://www.phds.org has many links (star-rated by users) to interesting articles.

If you want a different take on things, there is that virtual planet, the blogosphere. You can find out about the day-to-day life of graduate students (though crystal cultivators and the bench-bound be warned, some of your fellow biology graduate students spend their days in more tropical climes). Or you can read about anything from the graduate school experience from a female perspective (http://sciencewoman.blogspot.com/) to papers or seminars that inspired a peer. A list of interesting science-related blogs can be found at http://www.phds.org/graduate-school-success/blogs. There is also a regular column called 'Graduate Journal' on the Nature website, which follows a set of graduate students and ranges from practical insights into different stages of graduate school to poignant discussions of how science is affecting life.

Once you have met your virtual peers, there are of course your physical peers. Many universities help graduate students to meet both in social arenas and in journal clubs and student seminar series. The latter can help you get your feet wet with scientific presentations before you stand at that podium in front of the Society for X, Y or Z. Speaking of societies, many have events aimed at graduate students at their annual meetings, allowing students to mingle with each other and, often, with the directors of the society. In some countries, there are also societies for graduate students: for Europe, there is EURODOC (http://www.eurodoc.net), a federation of national associations of young researchers, and a useful website with good links even for students who don't live in a country with such a graduate student body.

Going back to face-to-face help, there is no substitute for finding mentors who can guide you through these years and advise you when times seem bad. Seeking out mentors may seem obvious, but lack of them can ultimately derail your research career altogether. With any luck, the head of your lab is one of these mentors, but on occasions this is not the case. As you choose a lab (either through the US-style rotation or the 'jump feet first into your research career' model favored in other countries), try to assess how available your potential advisor is. All advisors have some traveling and administrative obligations, so the technical and moral support of fellow labmatespost-docs, graduate students and technicians-is absolutely invaluable. In the end, independence and initiative are vital to successful $\mathrm{PhD}$ years, but sympathetic ears sure do help. In addition, in some countries and institutions, you will need to put together a thesis committee. This can be a fantastic source of technical expertise. Ideally, these people will help give you the big picture along with independent advice to guide your research path. Going straight to the bottom line, that hot-shot on your committee will make a good referee later; however you should also look for people with the time, energy and interest to carefully read your reports and thesis drafts and to advise you.

With good advice, initiative and a lot of work, you'll ultimately reach that emotional day when you present and defend your thesis, a day when there may even be a lump in the throat of your 'slave-driving' boss. It is a great achievement, but don't rest on your laurels: you may be heading for post-doctoral research or be moving away from a research track. That, my friend, is a discussion for another time. 